\title{
Erratum to: Recrystallization Behavior of CoCrCuFeNi High-Entropy Alloy
}

\author{
NOKEUN PARK, IKUTO WATANABE, DAISUKE TERADA, \\ YOSHIHIKO YOKOYAMA, PETER K. LIAW, and NOBUHIRO TSUJI
}

DOI: $10.1007 / \mathrm{s} 11661-015-2915-3$

(C) The Minerals, Metals \& Materials Society and ASM International 2015

\section{Erratum to: METALLURGICAL AND MATERIALS TRANSACTIONS A, VOLUME 46A, APRIL 2015, pp. 1481-1487 DOI: $10.1007 / \mathrm{s} 11661-014-2594-5$}

Nokeun Park's affiliation has been updated as shown in this erratum.

The third sentence in the following text has been added to the Experimental Procedures section on page 1482 as clarification regarding the chemical composition of the whole sample:
The material used in the current study was an equimolar $\mathrm{CoCrCuFeNi}$ alloy $(20 \mathrm{~mol}$ pct for each element) that was cast with the pseudo float melting process that brings almost homogeneous distribution of each element. ${ }^{[14]}$ An as-cast HEA rod $10 \mathrm{~mm}$ in diameter and $60 \mathrm{~mm}$ in length was homogenized at $1373 \mathrm{~K}$ $\left(1100{ }^{\circ} \mathrm{C}\right)$ for 12 hours, followed by water cooling. The chemical composition of homogenized specimen was measured by wavelength-dispersive X-ray spectroscopy, and the atomic percent was $\mathrm{Co}_{21} \mathrm{Cr}_{22} \mathrm{Cu}_{22} \mathrm{Fe}_{21} \mathrm{Ni}_{14}$.

NOKEUN PARK, Assistant Professor, is with the Department of Materials Science and Engineering, Kyoto University, Yoshida Honmachi, Sakyo-ku, Kyoto 606-8501, Japan, and also with the Department of Microstructure Physics and Alloy Design, Max-PlanckInstitute for Iron, Düsseldorf, Germany, and also with the School of Materials Science and Engineering, Yeungnam University, Gyeongsan 712-749, South Korea. Contact e-mail: nokeun_park@yu.ac.kr IKUTO WATANABE, Graduate Student, is with the Department of Materials Science and Engineering, Kyoto University. DAISUKE TERADA, Associate Professor, is with the Department of Materials Science and Engineering, Kyoto University, and Department of Mechanical Science and Engineering, Chiba Institute of Technology, Tsudanuma, Narashino, Chiba 275-0016, Japan, and also with the Elements Strategy Initiative for Structural Materials (ESISM), Kyoto University, Yoshida Honmachi, Sakyo-ku, Kyoto 606-8501, Japan. YOSHIHIKO YOKOYAMA, Associate Professor, is with the Institute for Materials Research, Tohoku University, Sendai, Miyagi 980-8577, Japan. PETER K. LIAW, Professor, is with the Department of Materials Science and Engineering, The University of Tennessee, Knoxville, TN 37996-2100. NOBUHIRO TSUJI, Professor, is with the Department of Materials Science and Engineering, Kyoto University, and also with the Elements Strategy Initiative for Structural Materials (ESISM), Kyoto University. Contact e-mail: nobuhiro-tsuji@mtl. kyoto-u.ac.jp

The online version of the original article can be found under doi: 10.1007/s11661-014-2594-5.

Article published online April 30, 2015 